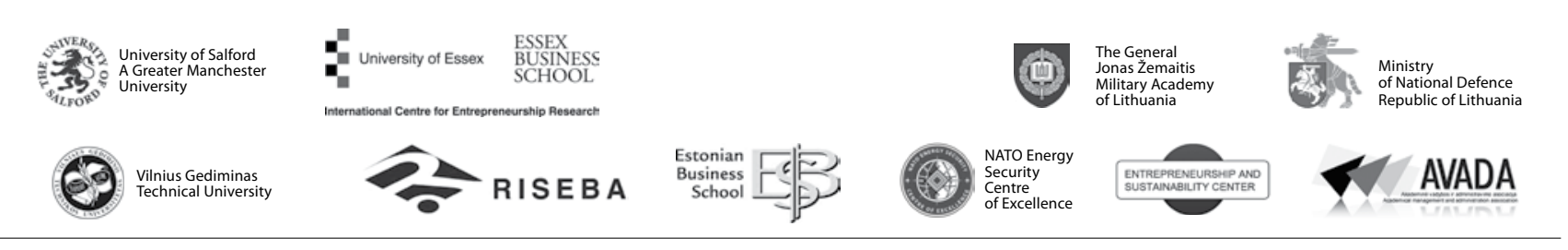

\author{
JOURNAL OF SECURITY AND SUSTAINABILITY ISSUES \\ ISSN 2029-7017 print/ISSN 2029-7025 online \\ 2017 March Volume 6 Number 3 \\ http://dx.doi.org/10.9770/jssi.2017.6.3(16)
}

\title{
BIOMASS CLUSTERS AS A NATIONAL ENERGY SECURITY FACTOR
}

\author{
Valentinas Navickas ${ }^{1}$, Mantas Švažas ${ }^{2}$, Jūratė Guščinskiené $\dot{3}^{3}$ \\ ${ }^{1,2}$ School of Economics and Business, Kaunas University of Technology, Gedimino str. 50, Kaunas, Lithuania \\ ${ }^{3}$ The General Jonas Žemaitis Military Academy of Lithuania, Šilo str. 5A, Vilnius, Lithuania \\ E-mails:1'valentinas.navickas@ktu.lt,.2mantas.svazas@ktu.edu,,3jurate.guscinskiene@lka.lt
}

Received 10 December 2016; accepted 27 February 2017

\begin{abstract}
The aim of the article is to explicate methodology, facilitating the evaluation of biomass cluster's impact to the growth of the energetic independence and national security. The analysis of the biomass clusters' impact to the energetic security is related to the critical analysis of the resources as well as to the analysis of the secondary data. The conception of a biomass cluster is relatively new as it emerged basically given the complex geopolitical situation and the aim of the pursuit for some energetic alternatives. The cluster unites enterprises, operating in some certain region and engaged in biomass preparation, logistics and burning. The main impetus of the cluster activity is the objective of the consumers' provision by some local renewable energy. Some serious issues, related to the energetic resources consumers' behaviour, are often occurring in the states where import-based structure of energy prevails. Lacking some competition and local production, both energetic and national state security is "walking with a limp". Under the above circumstances, a biomass cluster may become a counterweight from monopoly-based import, ipso facto, increasing national security of the state itself. In the latter case, some stable energy supply would be assured and the price would be based on the market but not on the shifts of the geopolitical situation. The authors have created the following research methodology, contributing the evaluation of the benefit of the local resources use.
\end{abstract}

Keywords: biomass clusters, energy security, energy autonomy (independence), sustainable development.

Reference to this paper should be made as follows: Navickas, V.; Svazas, M.; Guscinskiene, J. 2017. Biomass clusters as a national energy security factor. 2017. Towards food safety, Journal of Security and Sustainability Issues 6(3): 523-531.

http://dx.doi.org/10.9770/jssi.2017.6.3(16)

JEL Classifications: O12, O13, Q32, R58.

\section{Introduction}

Ideas of the renewable energetics, being developed more actively worldwide, are providing with the grounds for the increasing interest of the scientists to investigate the economic benefit, being framed from the energy, obtained from renewable resources. In the countries rich in natural biomass resources, it is more oriented towards the tests of the biomass use benefit. As various biomass kinds do exist, all that leads to the diversity of tests when separate fuel kinds' exploitation benefit characteristics are investigated. It is underlined that biomass is a clean renewable resource and some exceptional attention is to be paid to the sustainable fuel exploitation, nature-friendly and aiming namely at the utilisation of biomass waste.

Biomass cluster's activity is significantly connected with the raw materials the cluster is processing and converting into energy. It leads to a situation when two types of products, formed by the cluster, are existing. In the first case, primary products, i.e. the ones of the fuel, and in the second case, finished energy, obtained processing the fuel products, are assessed. The cost-price of the finished product depends on the primary type of the product; in every country it differs, depending on the renewable resources available in the country. Under 
expansion of spectrum of the industrial enterprises activities, new biofuel sub-categories are emerging, which later on are exploited for the production of energy.

It appears from researchers ' work that the fuel is most often classified according to the fuel framework, existing in a particular country. In some cases, some simplified framework, classifying fuels kinds according to their origin characteristics might be (Ilavsky, Oravec, 2000; Gavrilescu, 2008; Ciubota-Rosie, Gavrilescu, Macoveanu, 2008). Fuel products may be classified according to the way of exploitation (Balat, Ayar, 2005; Caputo, Palumbo, Pelagagge, Scacchia, 2005; Carneiro, Ferreira, 2012). Secondary products, related to final energy, are of the following three types: electricity, heat and natural gas (Bauen, Woods, Hailes, 2004; Borowski, 2008; Hämäläinen, Näyhä, Pesonen, 2011). The most common is the thermo-production technology, however, an opportunity to produce heat and power simultaneously by cogeneration techniques was provided with. The latest technology, i.e. gasification, allows the supply of natural, purified gas to the market, as well as the replacement of fossil natural gas which is exploited for the domestic use.

Therefore, the novelty of the paper is the fact that the impact of the cluster as a business inter-organisational relationship structure for the strengthening of the energetic and national security had been investigated. A cluster, using exceptionally local resources, contributes to the growth of security in the country. From the energetic point of view, the country becomes less dependent on the energy and fuel import, and the local manufacture encourages the economic growth and the diversion of resources for other areas, necessary to be financed at that moment. National security changes, caused by the renewable energy, currently are still under-investigated. In that case, the biomass cluster operation principle and its influence on the national security may be considered as a scientific innovation.

Therefore, the main goal of our study is to examine the impact of the biomass cluster to the energetic security. For that purpose, opportunities, allowing the cluster to contribute to the energetic security of the state and the regions, considering sustainable development principles, are investigated. The above principles are very important for the cluster's activity as waste, which is not possible to be processed, is utilised for the energy production. As well it is studied, what way biofuel of some particular kind may contribute to the creation of the economic benefit and simultaneously to the strengthening of the national energetic security in the country. The biofuel kinds, which are characterised by sufficient abundance and exploitation precedents in different states during the recent period, are studied. Therefore, the detailed objectives of the study are as follows:

- To present distinctive character of the biofuel cluster;

- To research the interaction of the biomass cluster and the energetic security;

- To analyse the impact of the biomass cluster to the energetic security of the country.

\section{Specific Features of the Biofuel Cluster}

Biofuel cluster specifics is entailed by various factors, determined by the emerging situation in different countries. Frequent situations do happen when the countries, dependent on the imported fossil fuel or energy, are seeking some alternatives which would increase the country's self-sufficiency in energy. In the major part of the states, abundant diverse biomass resources are available, the fuel itself is characterised by positive and balancing features. This is determined given namely biofuel as a possible alternative is chosen, especially in less developed countries with lack of high technologies. The most widely utilised biofuel strain is solid biomass, received during the processing of the round timber. However, and other biofuel kinds are started to be absorbed. Biomass resources include wood and wood waste, agricultural crops (i.e. short rotation woody, herbaceous woody, sugar and oilseed crops) and their waste by-products, municipal solid waste, residues from agro-industrial and food processes, aquatic plants such as algae and water weeds (Caputo, Palumbo, Pelagagge, Scacchia, 2005). Wider utilisation of the biofuel facilitates the expansion of the local manufacture and maintains stable energy prices.

Biomass cluster as the entire conception of the cluster is a relatively new phenomenon in the business world. Business clusters are by no means the invention of the $21^{\text {st }}$ or even the $20^{\text {th }}$ century. The prototype of a cluster is 
the industrial district, characterised by Alfred Marshall as early as 1890 in his work "Principles of Economics" (Marshall, 1920). The biomass cluster three important activity levels: provision with biofuel, biofuel burning and research institutions, providing with activity efficiency solutions. The biomass cluster is oriented towards the meeting of energetic needs of some particular country region, unlike the majority of business clusters which are oriented towards the foreign consumer. Given the cluster activity field is local, it includes huge human and capital resources. Pursuant to Milanović, Mihailović, Paraušić (2010), different clusters' functioning elements, which simultaneously are relevant and for biomass clusters, are distinguished:

1. Base businesses- businesses that are the leading participants in the cluster and most often bring the biggest profits from users outside the cluster.

2. Support businesses- businesses that directly and indirectly support the base cluster businesses. These include suppliers of specialized machines, components and raw materials, as well as other service firms, including financial/brokerage firms and their capital, attorneys, designers, marketing and public relations firms. These firms are usually highly specialized and physically located close to the base business firms.

3. Intellectual support infrastructure - in clusters that operate on the top level, the base and support businesses do not work separately, in isolation. Many local community members participate in successful clusters: local schools, universities, political institutes, local commercial and professional associations, economic development centers and many others that support the cluster's activities and are in fact key cluster actors.

4. Physical support infrastructure - this is, before all, the physical infrastructure: roads, ports, ordered waste disposal facilities for classic or specific waste, communication links, etc. The quality of this infrastructure must be at least on the same level as that of the competition, although it is desirable that it be even better.

All the above elements are prerequisite for the biomass cluster as its activity efficiency maximum is when its activity is performed in a radius of $100 \mathrm{~km}$. The distance like that assures that the cost-price of the biofuel will remain optimum and the time elapsed from the biomass preparation to its burning will meet the specified standards. The intellectual infrastructure, i.e. research establishments, economic development centres, assuring that the efficiency processes are to be ongoing, facilitating to decrease the cost-price of the energy sale, plays an especially important role.

The biocluster is characterised by great economic importance. As this is a local cluster, its benefit is experienced primarily by the operation region. Waste disposal, solution of social issues, increased energy flows of local manufacture - these are only some items of the cluster benefit. Alongside other business clusters, the biomass cluster may decrease incentives for new business formation due to increased competition and crowdingout effects (or congestion costs) that result in diminishing marginal returns to entrepreneurial opportunities. Others claim clusters might lower the cost of starting a business by providing specialized suppliers, a local customer base, and producers of complementary products and services (Slaper, Harmon, Rubin, 2016). This is an additional activity efficiency trend - a cluster, generating resources of own members, refers them to the direction which would assure the lowest product's cost-price and would maximise the cluster members' benefit. Simultaneously, some over-investment situations are avoided when the cluster members are investing into the same facilities, therefore, wasting the financial resources. Instead of that, it is concentrated on the placing of an attractive product on the market, decreasing its cost-price and adapting to the market prices.

Biomass cluster activities go hand in hand with sustainable development principles. The cluster's activities assure that natural waste, which is unable to be processed in the other way, will be used for the energy production. Sustainable exploitation of resources is a prerequisite of the cluster's activities; all this distinguishes it in the context of other energy producers. Able to create economic and financial value from unprocessed biological waste, the cluster becomes an important economic entity, forming energetics policy at the regional level of the country. The following key sustainability indicators which are noticed in the activity of the biomass cluster are (Evans, Strezov, Evans, 2009):

1. Price of energy generation unit must be considered since unfavourable economics are not sustainable.

2. Efficiency of energy transformation must be known for meaningful comparison.

3. Land use requirements are important as renewable energy technologies are often claimed to compete with agriculturally arable land or to change biodiversity. 
4. Social impacts are important to correctly identify and quantify the human risks and consequences will allow better acceptance and understanding of some technologies that are often subject to public objection.

Biomass clusters are being evolved in more developed states as they are looking for ways how to correct own energetic structure under the changing environmental requirements. However, there are cases, when the countries are converting to the biofuels, decreasing their dependency on the imported fuel and energy. Table 1 presents developed and developing countries clusters' experience globally. It is submitted what key strengths do prevail in particular countries and what is missing in order to achieve some breakthrough in the area of the renewable resources manufacture.

Table 1. Biomass Clusters' Strengths and Weaknesses in the World Countries (Näyhä et al., 2009).

\begin{tabular}{|c|c|c|c|c|c|}
\hline & Brazil & Canada & Finland & Sweden & U.S. \\
\hline 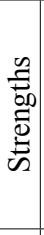 & $\begin{array}{l}\text { Forestry activities } \\
\text { Know-how Col- } \\
\text { laboration between } \\
\text { industries,research } \\
\text { centres and technol- } \\
\text { ogy providers }\end{array}$ & $\begin{array}{l}\text { Availability of bio- } \\
\text { mass } \\
\text { Existing infrastructure } \\
\text { Existing supply chain }\end{array}$ & $\begin{array}{l}\text { Technological and } \\
\text { chemical know-how } \\
\text { Availability of biomass } \\
\text { Raw material logistics }\end{array}$ & $\begin{array}{l}\text { Knowledge of biomass } \\
\text { handling } \\
\text { Process expertise } \\
\text { Existing infrastructure } \\
\text { Technological leadership }\end{array}$ & $\begin{array}{l}\text { Ability to harvest, transport } \\
\text { and handle large amounts of } \\
\text { woody biomass } \\
\text { Biomass availability } \\
\text { Process engineering expertise }\end{array}$ \\
\hline 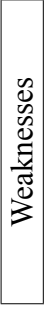 & $\begin{array}{l}\text { Lack of R\&D } \\
\text { Competition for raw } \\
\text { material } \\
\text { Inflexibility of pulp } \\
\text { and paper sector } \\
\text { Environmental sus- } \\
\text { tainability }\end{array}$ & Lack of capital & $\begin{array}{l}\text { Lack of public and } \\
\text { private funding } \\
\text { Low investment capa- } \\
\text { bility } \\
\text { Change resistance } \\
\text { New business area and } \\
\text { technologies outside } \\
\text { actual competence }\end{array}$ & $\begin{array}{l}\text { Change resistance from } \\
\text { 'business as usual' } \\
\text { (inability to grasp } \\
\text { new possibilities) }\end{array}$ & $\begin{array}{l}\text { Risk aversion Change resis- } \\
\text { tance } \\
\text { (conservative industry) } \\
\text { Lack of vision }\end{array}$ \\
\hline
\end{tabular}

Biofuel cluster's specifics not only allows to enhance the economic welfare but also develops national and energetic security growth conditions. Energetic security and stable energy supply are the most important conditions, assessing country's national security, its attractiveness for business and preparation for emergencies. The coherence of the biomass clusters' activity and the energetic security is close given successful clusters" activities assure the energetic security growth which is felt at the national level as well. Under the decrease of the energetic resources imports and the increase of the local energy manufacture, the energetic self-sufficiency growth provides with the assumptions for the heightened national security.

\section{Biomass Clusters' Activity and Energetic Security Coherence}

The countries take various measures, which encourage some diversity of the energy supply, to increase the energetic security. In one case, the countries are building up new energy transportation networks, seeking to diversify the imports; in the other case, they are building power stations which exploit more fossil fuel, though the fuel like that is imported from the other states. In the third case, local manufacture is strengthened but it is based on the utilisation of the renewable resources.

The biomass cluster's coherence with the energetic security is expressed in the following three trends:

1. Decrease of energy imports. Biofuel cluster, executing its activity, increases the energy manufacture inside the country and this helps to decrease the energy import from the third countries. The main economic condition of the above situation is that the energy from the renewable resources is to be produced at a competitive price. Cases do exist when the state makes a decision to subsidise the local energy production, however, this is more applied to the other solutions, related to the utilisation of other renewable resources but not the biofuel, which essentially is cost-effective. Under the decrease of the energy imports, some possible energy supply instability is prevented in the energy export markets, especially in the case of some geopolitical disagreement. As well, the consumed energy structure is being diversified and this eliminates opportunities of the external market monopolisation.

2. Decrease of energetic resources import. One of the energetic fuel import kinds, e.g. of gas, fuel oil, may 
be the import for the energy production inside the country. Biofuel clusters, manufacturing the energy from the renewable resources, provide with opportunities for the decrease of the above fuel, the one of the higher price, quantity and for the increase of the total green energy quantity. The decrease of the fuel import allows to avoid a situation when the supplier - monopolist unilaterally rises the fuel prices, and the country, having no opportunity to import some fuel from free markets, is made to agree with the conditions, specified by the monopolist. Simultaneously, the environmental pollution is nosediving and the level of costs for emission allowances is dropping; the energy manufacture adapts to the internal needs of the country but not to the volume of the fuel import contracts. This is exceptionally relevant when in some contracts with regards to the fuels, the "take-or-pay" condition is applied.

3. Growth of local energy manufacture from non-recoverable waste. For a long time, biological waste and its secondary utilisation were the most acute problems in the environmental policy of the states. However, the rising technological level and the growth of the raw materials' prices caused a situation when simultaneously two problems, i.e. inside the country energy produced from biological waste as well as its disposal, are being solved. The biomass cluster's activity allows to achieve a synergy effect, i.e. inside the country, the increased energy manufacture provides with the conditions for the disposal of various biological waste which may be burned, digested or processed in other way, and the derived energy is supplied to the market.

Biomass cluster is to be related to the energetic security and via the assurance of the sustainable growth. On the grounds of the sustainable development growing country may achieve stable economic outcomes, simultaneously, increasing the society prosperity. Energetic provision plays an important role in the country as under the growth of the human needs of the energy consumption, it is obligatory to maintain the balance between the energy supply alternatives. A clear policy, which would facilitate to identify trends of the national energetics development, is necessary that not to lead to a deterioration of the national energetics and national security situation. Due to the increasing number of countries, using renewable resources and, meanwhile, decreasing reserves of the fossil fuel, the biomass cluster, operating according to the sustainable development principles, would allow to maintain citizens' provision with the energy and, under the changes of the energetic situation, to strengthen the national energetic security. Pursuant to Del Rio, Burguillo, (2008), a sustainable regional (local) policy must tackle the three dimensions of sustainability with the aim to increase the standard of living of its citizens:

1. Environmental. Reduction of local pollution, exploitation of the natural resources in the territory and maintenance of the resilience (ability to adapt to change), integrity and stability of the ecosystem.

2. Economic. Increase of regional per capita income, improvement in the standard of living of the local population, reduction of energy dependence and increase in the diversification of energy supply.

3. Social. Some authors stress that SD cannot be achieved without the sustainability of social and cultural systems, which includes the achievement of peace and social cohesion, stability, social participation, respect for cultural identity and institutional development. Reducing unemployment and improving the quality of jobs (more permanent jobs), increasing regional cohesion and reducing poverty levels are key actions at local level to achieve social sustainability. Activities such as renewable energy deployment, which are an alternative to traditional agriculture, should be encouraged. This has a particularly positive psychological impact on the prospects of the young local population.

More and more actively debating on the climate change impact for the environment, energetic security assurance becomes a more relevant issue. Various decisions are made to protect long-term energy supply, nowadays; one of the above options may be utilisation of the biofuels. However, a balance between the fossil and renewable energetics is necessary at the moment, as the latter cannot replace the fossil fuel entirely due to the shortage of the technologies and due to the relatively high cost-price of the power stations' equipment. According to these requirements, policies supporting the long-term security of energy supply should ensure (Turton, Barreto, 2006):

1. The existence of a regional domestic oil and gas extraction industry which is able to expand rapidly in order to exploit domestic resources if necessary;

2. The availability of regional resources that insufficient to supply current levels of regional consumption for a period of at least 20 years; furthermore, it is required that a buffer for 20 years of projected consumption exists at the end of the century. 
Biomass cluster may increase the national security as both the fuel and the technologies used may be extracted inside the country, independently on the impingement of foreign states. However, the level of prices plays the essential role. If the price of the biomass cluster's supplied energy is competitive, it may replace the fossil fuel and strengthen the national energetic security. Referring to Loschel, Moslener, Rubbelke, 2010), security of energy supply exists if at least current volumes of energy are available in the short and medium term at prices which do not significantly exceed past medium-term price-trend levels. Having achieved the optimum price of the renewable energy, a coherence between the biomass cluster and the energetic security in the context of the national security occurs. Maintaining the stability of the prices, assumptions for the energetic security growth are formed given stable energy supply and local energy manufacture allow to direct the means for the satisfaction of other entities needs. At the same time, the cluster may contribute to the sustainable development expansion as its activities shall integrate private and public sectors. Following Tunčikienè, Skačkauskienė, Grenčiková (2013), ideas of the sustainable development shall increase the efficiency of the public institutions and the activity rationality.

The biomass cluster is characterised by a clearly expressed supply chain, which facilitates the assurance of the continuous biofuel supply for the power stations. Besides, the cluster may manage various problem-based situations which may arise in the case of the imported fossil fuel. Utilisation of the biofuel inside the country assures increased mobility, the ability to react to the changed energy demand in the region. Likewise, the cluster generates and other kind of benefit (Lam, Varbanov, Klemeš, 2011):

1. Partitioning of the solution space and problem decomposition. This allows breaking down the initial complex problem into several problems of smaller size and complexity, greatly facilitating the modelling and solution efforts.

2. Reducing the scope and size of the problems to consider allows adding more details and precision to the process models, and increasing the confidence in the resulting supply chain networks.

The coherence, existing between the cluster activities and the energetic security is close and this allows seeking the growth of the national security. The multiplier effect, following the sustainable development principles, creates an opportunity to strengthen the national security and exploit biological resources available. In the practical approach, the biomass clusters' impact for the energetic autonomy arises through the exploitation of the local resources and, therefore, through the decreased energy or fuel import share. Thus, energy production and supply chain is better controlled; higher economic value is created inside the country.

\section{Biomass Clusters' Impact on Energetic Autonomy}

For the assessment of the energetic autonomy several kinds of biofuel are applied. Their use helps to enhance energetic autonomy, solve environmental issues, decrease import of energy resources. For the assessment a model of Lithuania is used. During the last five years the country has significantly decreased the volume of the energy resources imports, replacing natural gas by various types of biofuels. This has lead to the improvement of the national economic situation as well as to the increase of the national security because the competition in the energetics market and decreasing energy prices have allowed to reclassify the resources into other streamlines. It has not only improved the national economic situation but and increased the national security as the competition in the energetics market and decreasing energy prices allowed to reclassify the resources into other directions.

In the research, the benefit of the exploitation of three fuel kinds is investigated together with the analysis of energy manufacture savings when the gas equipment is replaced by boilers, using the biofuels. Primarily, benefit of the solid biomass disposal is analysed. The major part of the solid biofuel used in the new power stations would be supplied by the cluster members, the majority of which would be made by small-sized supply companies or farmers, possessing biomass resources. Under the exploitation of the local resources, a great amount of entities would earn additional income and would ensure the creation of the updated value. The abundance of the cluster members would allow to ensure the continuous biofuel supply for the plants. The biofuel-disposalfrom-the-other-resources benefit is calculated according to the following formula: 
Other examined fuel kind is the waste water sludge. Though the sludge quantities are high enough, its utilisation opportunities are under-applied in practice nowadays, in the absence of some legal regulation and political will. Since the sludge is not sold as a fuel but utilised as waste, the disposal benefit occurs under the replacement of the timber biofuel, commonly used for the energy production, by the sludge. In the above case, for the evaluation of the economical benefit, a theoretical sludge tone price equal to EUR 100, which indicates the benefit created by the utilisation of the sludge instead of its storage in the outdoor areas, is chosen. The sludge disposal benefit is calculated according to the following formula:

Another popular biofuel kind is straw. It may be burned unprocessed or in the shape of briquettes. It may be mixed together with by-products left as waste after cleaning the grains (shives), therefore, obtaining the fuel synergy, several kinds of fuel burning in one place. The studies show that in Lithuania 120,000 tne straw may be burned annually, and in the above case, it is estimated that slightly more than a half of the above indicated quantity will be burned. Other part would remain in the fields aiming at recovering positive humus balance of the agricultural lands. Straw utilisation benefit is calculated as follows:

Savings of the energy manufacture are formed, therefore, the energy is produced in a more efficient way as condensing economisers serve for that target. When the energy from gas or fuel oil is produced, energy manufacture efficiency hardly amounts 90 percent and the yield of hot smoke to the air is making the air warmer. The economiser facilitates the extraction of the heat from the smoke and it is diverted back to the heating systems. This increases the efficiency of the energy manufacture over 100 percent. The total sum of the energy manufacture savings is calculated according to the formula:

Prior bought gas quantity is considered the quantity which will be replaced by the biofuel from now. It is considered that the saving due to the activities of the economisers equals 10 percent. The gas price is chosen referring to the prevailing price of the natural gas, purchased from the foreign suppliers.

Below the characteristics of the price and the quantity (Table 2), allowing performance of the research actions, are submitted as well. Exploiting the biofuel, the net benefit, created inside the country, is obtained and the energy manufacture savings are reflected in the saved financial resources.

Table 2. Biofuel Cluster's Strengths and Weaknesses in the World States (Composed by the authors referring to Lithuanian District Heating Association (LDHA) and Baltpool data))

\begin{tabular}{|l|r|c|}
\hline & Quantity & Price, EUR \\
\hline Solid biomass & 600,000 & 150 \\
\hline Sludge & 25,000 & 100 \\
\hline Straw & 70,000 & 120 \\
\hline Energy manufacture savings & 137,480 & 230 \\
\hline
\end{tabular}

Further analytic actions are made. Calculating the long-term benefit, when the inflation reaches 2 percent, the biomass clusters' economic benefit is evaluated according to the methodological instrument drawn. The highest benefit for the rural locations is brought by the traditional timber biofuel exploitation and creation of new jobs. The ultimate benefit via the increased state's competitiveness, exploiting local fuels, is best felt by the society (Table 3).

Table 3. Economic Biomass Clusters` Benefit for Rural Locations

\begin{tabular}{|l|r|r|r|r|}
\hline \multicolumn{1}{|c|}{ Revenue type } & \multicolumn{1}{c|}{ Total } & \multicolumn{1}{c|}{$1-3$} & \multicolumn{1}{c|}{$4-10$} & $11-15$ \\
\hline Sludge disposal benefit & 40.200 .829 & 6.000 .000 & 18.957 .422 & 15.243 .406 \\
\hline Straw utilisation benefit & 131.714 .785 & 16.800 .000 & 63.696 .940 & 51.217 .844 \\
\hline Benefit of solid biomass disposal & 1.446 .229 .837 & 215.000 .000 & 682.467 .214 & 548.762 .622 \\
\hline Energy manufacture savings & 438.650 .396 & 62.496 .000 & 208.501 .317 & 167.653 .079 \\
\hline IN TOTAL: & 2.056 .795 .847 & 300.296 .000 & 973.622 .893 & 782.876 .951 \\
\hline
\end{tabular}


Total economic benefit sum indicates what kind of benefit may be created under the expansion of the biomass cluster in the regional municipalities where the heat energy is manufactured using the imported fossil fuel. Huge benefit is evident, having evaluated the disposal of the timber from the cluster members, inasmuch as this leads to the creation of new jobs; their created benefit is reflected as well. The economic benefit is closely interrelated to the social benefit as an opportunity to improve living conditions in the regions, to raise the infrastructure level, to invest into the necessary areas for the rural residents. All the above contributes to the strengthening of the national security and the opportunity to buy energy at a competitive price.

\section{Conclusions}

The main biomass clusters' specifics is the re-use of the waste as raw materials and therefore the added value is generated. This especially serves under challenging political and economic circumstances when it is obligatory to assure the stable energy supply at a competitive price. The cluster's activity is innovative and its key activity prerequisite is following the principles of the sustainable development. As the cluster brings together various-type companies, operating in the sector, they may share the resources, the information, the beneficial experience and, therefore, open ways for the creation of a new and greater value. It would be impossible to create the above value, in the case if the cluster's companies worked separately.

The biomass cluster's significance is reflected not only in the economy but also in the approach of the national energetic security. Exploiting the local fuel, sudden price rises are avoided, imports from instable markets, which may use the fuel and energy prices as a political pressure instrument, is decreased. Utilisation of the biofuel encourages deep economic and social processes in the country, thus, preventing some possible social unrest and disruptions of the energy import. Since the entire supply chain does not overcome the board of the country as well as the limits of some separate region, it is possible to maintain the balance in provision with the necessary energy and avoid its supply disruptions, not related to the national energy system.

The biomass cluster's impact to the energetic security occurs via the disposal of the unused waste for the energy manufacture, therefore, decreasing the energy import. It is possible that instead of the energy import, the import of the fossil fuel, used for the energy manufacture inside the country, would be decreased. The greatest value is created by the utilisation of the solid biomass, however, a very important element is energy manufacture savings as well. They are being formed during the investments into more efficient equipment, using the biofuel and allowing to extract the heat from the smoke as well. The above equipment is replacing the equipment, using the natural gas, therefore, decreasing its import and increasing the energetic security level.

\section{References}

Balat, M.; Ayar, G. 2005. Biomass Energy in the World, Use of Biomass and Potential Trends. Energy Sources, 27(10): 931-940.

Borowski, P. 2008. Development Strategy of Electricity Production from Biomass. 10th International Congress on Mechanization and Energy in Agriculture, 14-17 October 2008, Antalya-TURKIYE. 438-440.

Caputo, A.C.; Palumbo, M.; Pelagagge, P.M.; Scacchia, F. 2005. Economics of biomass energy utilization in combustion and gasification plants: effects of logistic variables. Biomass and Bioenergy, 28(28): 35-51.

Carneiro, P.; Ferreira, P. 2012. The economic, environmental and strategic value of biomass. Renewable Energy, 44(44): 17-22.

Ciubota-Rosie, C.; Gavrilescu, M.; Macoveanu, M. 2008. Biomass - an important renewable source of energy in Romania. Environmental Engineering and Management Journal, 7(5): 559-568.

del R1o, P.; Burguillo, M. 2008. Assessing the impact of renewable energy deployment on local sustainability: Towards a theoretical framework. Renewable and Sustainable Energy Reviews, 12(12): 1325-1344.

Energy resources market „Baltpool“. http://www.baltpool.lt

Evans, A.; Strezov, V.; Evans, T.J. 2009. Assessment of sustainability indicators for renewable energy technologies. Renewable and Sustainable Energy Reviews, 13(13): 1082-1088. 
Gavrilescu, M. 2008. Biomass power for energy and sustainable development. Environmental Engineering and Management Journal, 7(5): 617-640.

Hämäläinen S.; Näyhä A.; Pesonen H.L. 2011. Forest biorefineries - A business opportunity for the Finnish forest cluster. Journal of Cleaner Production, 19(19):1884-1891.

Ilavsky, J.; Oravec, M. 2000. Utilization of biomass in Slovakia. Ecological Engineering, 16(16): 83-89.

Lam, H.L.; Varbanov, P.S.; Klemeš, J.J. 2011. Regional renewable energy and resource planning. Applied Energy, 88(88): 545-550.

Loschel, A.; Moslener, U.; Rubbelke, D.T.G. 2010. Indicators of energy security in industrialised countries. EnergyPolicy, 38(38): 16651671.

Marshall, A. 1920.Principles of Economics. London: Macmillan and Co. 8th ed.

Milanović, M.; Mihailović, B.; Paraušić, V. 2010. Processes of business incubation and clusterization to support the creation of a network economy in Serbia. Megatrend Review, 7(2): 5-20.

Näyhä, A.; Hämäläinen, S.; Pesonen, H. 2009. Biorefineries e Future Business Opportunity for Forest Cluster. Diffusion of Forest Biorefineries in Scandinavia, North America and South America. University of Jyväskylä. Reports from the School of Business and Economics No 39/2009.

Slaper, T.F.; Harmon, K.M.; Rubin, B. 2016. Industry clusters and regional economic performance:. A study across U.S. metropolitan statistical areas.

The Lithuanian District Heating Association (LDHA). 2013. Biokuro potencialo Lietuvoje ịvertinimas, biokuro kainu prognozé, biokuro panaudojimo socialinès naudos ịvertinimas ir biokuro panaudojimo plètrai reikalingu valstybès intervenciju pasiülymai. http://www.lsta. 1t/files/studijos/2013\%20met\%C5\%B3/A-80_biokuras\%20-\%20galutine\%20ataskaita3.pdf

Tunčikienė, Ž., Skačkauskienė, I., Grenčiková, A. 2013. Sustainable development of public sector: the state and assumptions of improvement of functional review in public institutions. Journal of Security and Sustainability Issues, 3(1): 11-21.

Turton, H.; Barreto, L. 2006. Long-term security of energy supply and climate change. Energy Policy, 34(34): 2232-2250. 